\title{
Aplicação dos instrumentos de gestão e manejo integrado da bacia hidráulica do açude Sumé, Paraíba
}

\author{
Application of management and integrated management instruments for the Sumé reservoir \\ hydraulic basin, Paraíba \\ Aplicación de instrumentos de gestión y gestión integrada para la cuenca hidráulica del embalse del \\ Sumé, Paraíba
}

Recebido: 16/01/2021 | Revisado: 20/01/2021 | Aceito: 30/01/2021 | Publicado: 07/02/2021

\author{
Igo Marinho Serafim Borges \\ ORCID: https://orcid.org/0000-0002-3662-1859 \\ Universidade Estadual da Paraíba, Brasil \\ E-mail: igomarinho27@gmail.com \\ Amanda Cristiane Gonçalves Fernandes \\ ORCID: https://orcid.org/0000-0001-8462-6171 \\ Universidade Federal de Campina Grande, Brasil \\ E-mail: amandafernandestt@gmail.com \\ Patrícia Luana Araújo dos Santos \\ ORCID: https://orcid.org/0000-0002-9258-3842 \\ Universidade Estadual de Campina Grande, Brasil \\ E-mail: patricialuannaaraujo@gmail.com \\ Emanuelly Cristovão Barbosa da Silva \\ ORCID: https://orcid.org/0000-0003-3835-1132 \\ Universidade Estadual da Paraíba, Brasil \\ E-mail: cristovamemanuelly@gmail.com \\ Sandro Sanches dos Santos \\ ORCID: https://orcid.org/0000-0001-8778-8619 \\ Universidade Estadual da Paraíba, Brasil \\ E-mail: sandrosanches27@gmail.com \\ Magna Jussara Rodrigues Santos \\ ORCID: https://orcid.org/0000-0001- 8026-6607 \\ Universidade Estadual da Paraíba, Brasil \\ E-mail: magna.santos@ aluno.uepb.edu.br \\ Fernanda Mariano de Lima \\ ORCID: https://orcid.org/0000-0002-7709-4493 \\ Universidade Estadual da Paraíba, Brasil \\ E-mail: fernandamariano.227@gmail.com \\ Jean Oliveira Campos \\ ORCID: https://orcid.org/0000-0002-2874-754X \\ Universidade Estadual da Paraíba, Brasil \\ E-mail: jeannolliveira@gmail.com \\ Henrique Sabino da Silva Pereira \\ ORCID: https://orcid.org/0000-0002-1328-8694 \\ Universidade Estadual da Paraíba, Brasil \\ E-mail: henriquesabinop@gmail.com \\ Jucianny Araújo da Silva \\ ORCID: https://orcid.org/0000-0001-8199-9212 \\ Universidade Estadual da Paraíba, Brasil \\ E-mail: juciannyaraujo@gmail.com \\ Paulo de Souza Albuquerque Junior \\ ORCID: https://orcid.org/0000-0003-0704-7998 \\ Universidade Estadual da Paraíba, Brasil \\ E-mail: paulojuniorh13@gmail.com \\ José Edvan dos Santos \\ ORCID: https://orcid.org/0000-0003-0524-578X \\ Universidade Estadual da Paraíba, Brasil \\ E-mail: joseedvandossantos@hotmail.com
}

\section{Resumo}

Está pesquisa tem como objetivo discutir e analisar as formas de manejos integrados de uma bacia hidráulica no município de Sumé, fazendo levantamento de informações recentes com a finalidade de manter em equilíbrio os 
recursos hídricos. Para tanto, utilizou-se o recurso metodológicos de levantamento bibliográfico e aplicação de manejo integrado subdividido em plano diretor dos recursos hídricos, sistemas de informações, enquadramento dos corpos hídricos, outorgado e cobranças. Como resultado obtido destaca-se que a água não encontra-se em conformidade com os padrões de potabilidade para consumo preestabelecido pela Portaria 29147/11 do MS e a Resolução 357/05 do CONAMA, segundo estudo realizado com amostra de água da bacia, além disso segundo uma pesquisa realizada com os consumidores da água provinda da bacia de Sumé, segundo eles a água apresenta alterações perceptíveis na sua composição segundo o cheiro e a turbidez da água oferecida pelo sistema de abastecimento e Companhia de Águas e Esgotos da Paraíba-CAGEPA. Diante dos resultados alcançados em toda a pesquisa, concluise que é possível, dentro do quadro ambiental existente, mudar a forma de apropriação e uso dos recursos ambientais sem deixar de fornecer esse recurso aos seres humanos com a qualidade necessária para o consumo, sem encontrar irregularidades no abastecimento segundo a qualidade da água.

Palavras-chave: Conservação ambiental; Bacia hidrográfica; Qualidade de água.

\begin{abstract}
This research aims to discuss and analyze the forms of integrated management of a hydraulic basin in Sumé, making a survey of recent information in order to keep water resources in balance. To this end, we used the methodological resource of bibliographic survey and application of integrated management subdivided into a master plan for water resources, information systems, water bodies framework, granted and collections. As aresult, it is noteworthy that the water did not comply with the consumption potability standards established by Ordinance 2914/11 of the MS and Resolution 357/05 of CONAMA, according to a study carried out with a sample of water from the basin, in addition according to a survey conducted with consumers of water from the Sumé basin, according to them the water shows noticeable changes in its composition according to the smell and turbidity of the water offered by the supply system and the Paraíba-CAGEPA Water and Sewage Company. In view of the results achieved throughout the research, it is concluded that it is possible, within the existing environmental framework, to change the form of appropriation and use of environmental resources, while providing this resource to human beings with the necessary quality for consumption without finding irregularities in supply according to water quality.
\end{abstract}

Keywords: Environmental conservation; Watershed; Water quality.

\title{
Resumen
}

Esta investigación tiene como objetivo discutir y analizar las formas de gestión integral de una cuenca hidráulica en Sumé, realizando un relevamiento de información reciente con el fin de mantener en equilibrio los recursos hídricos. Para ello, se utilizó el recurso metodológico de levantamiento bibliográfico y aplicación de gestión integrada subdividido en un plan maestro de recursos hídricos, sistemas de información, marco de masas de agua, concesiones y colecciones. Como resultado, se destaca que el agua no cumplió con los estándares de potabilidad de consumo establecidos por la Ordenanza 2914/11 de MS y la Resolución 357/05 de CONAMA, según un estudio realizado con una muestra de agua de la cuenca, además encuesta realizada a consumidores de agua de la cuenca del Sumé, según ellos el agua presenta cambios notables en su composición de acuerdo al olor y turbidez del agua que ofrece el sistema de abastecimiento y la Empresa de Agua y Alcantarillado Paraíba-CAGEPA. A la vista de los resultados alcanzados a lo largo de la investigación, se concluye que es posible, dentro del marco ambiental existente, cambiar la forma de apropiación y uso de los recursos ambientales, al tiempo que se brinda este recurso al ser humano con la calidad necesaria para el consumo sin encontrar irregularidades en el suministro según la calidad del agua.

Palabras Clave: Conservación medioambiental; Cuenca hidrográfica; Calidad del agua.

\section{Introdução}

No Brasil, a gestão de recursos hídricos foi implantada historicamente a partir da implantação do acordo Dublin na Rio-20 que teve como uma das principais ações a implantação da gestão dos recursos hídricos levando em consideração os aspectos econômicos, físicos e sociais do território da bacia hidrográfica (Porto \& Porto, 2008). Segundo Santos, (2020) Tal implantação foi concretizada através da lei $\mathrm{n}^{\circ}$ 9.433, de janeiro de 1997 que garantiu ao Brasil a implantação da política pública de recursos e organização hídrica denominada como: Política Nacional de Recursos Hídricos (PNRH) que classificou os principais instrumentos do manejo integrado de bacia hidrográfica como: Plano diretor dos recursos hídricos, sistema de informações, enquadramento dos corpos hídricos, outorga e cobrança (Foleto, 2018; Porto \& Porto, 2008).

Sobre isso Teodoro (2007) acrescenta que está lei traz a definição da bacia hidrográfica sendo como "uma unidade de estudos e gestão" por sua vez, Porto e Porto (2008); Cardoso et al., (2006) diz que a bacia hidrográfica pode ser considerada como sendo uma "área de captação natural de água oriunda da precipitação que faz convergir por escoamento para um único ponto de saída". Estas estruturas hídricas requerem proteção e conservação de forma continua tendo como órgãos responsáveis 
aqui no Brasil os Estados e a União que dividem entre si a tutoria das bacias hídricas brasileiras, o que, de certa forma, geram dificuldades na organização da gestão hídrica já que faz-se necessário uma gestão compartilhada com a administração pública e órgãos de saneamentos institucionais e que podem diferenciar-se da bacia hidrográfica (Porto \& Porto, 2008).

Tal cenário, pode ser encontrado na bacia de drenagem do Açude Sumé que veem sofrendo com problemas de falta de gestão, conservação dos seus recursos naturais e o comprometimento da qualidade dos corpos hídricos (Silva, 2016). Com efeito, pesquisas comprovam que o esvaziamento do açude público de Sumé e a subsequente falência do perímetro irrigado em 1989 estão diretamente relacionados à falta de políticas de planejamento e de gestão dos recursos hídricos, somados ainda às variações climáticas (Amorim, 2017).

Deste modo, esta pesquisa tem como objetivo discutir e analisar as formas de manejos integrados de uma bacia hidráulica no município de Sumé, possibilitando uma caracterização atualizada desta bacia e aplicação dos principais instrumentos de manejo. Analisando assim os seguintes aspectos: índice de precipitação pluviométrica e turbidez da água além dos dados públicos que permitem o conhecimento sobre as ações necessárias para a gestão hídrica do açude de Sumé para melhor atender a população estes dados, são de extrema importância por permitir uma melhor gestão e tomada de decisões na área rural e urbana, bem como possibilita ações mitigadoras no combate aos efeitos das ações antrópicas.

\section{Metodologia}

A metodologia da pesquisa baseia-se em leitura e análise de literaturas específicas e instrumentos de gestão dos recursos hídricos, buscando o desenvolvimento sustentável de tal prática. as subseções que seguem, portanto, abordarão aspectos relacionados à tipologia da pesquisa, bem como aos procedimentos adotados para a realização da coleta de dados. além dos dados necessários para obtenção dos resultados.

\subsection{Caracterização da área de estudo}

A bacia do açude de Sumé em estudo está localizada no município de Sumé-PB, na Microrregião do Cariri Ocidental paraibano, de coordenadas geográficas $7^{\circ} 40^{\prime} 18^{\prime \prime} \mathrm{Sul}, 36^{\circ} 52^{\prime} 54^{\prime}$ ' Oeste (Figura 1). Atualmente o suprimento hídrico é feito através do Açude Público Federal Sumé, com capacidade total de armazenamento de 44.864 .100 m³ (AESA, 2019).

Esse reservatório foi estudado, projetado e construído visando ao seu aproveitamento para fins múltiplos de irrigação, abastecimento d'água, agricultura de áreas de vazantes e piscicultura, além de parcial controle de cheias (Calado, 2020). A bacia hidráulica é de esfera federal localizada no alto curso do Rio Paraíba. Com volume atual de $1.806 .606 \mathrm{~m}^{3}$ e volume total de $4,03 \%$ (AESA, 2019). 
Figura 1. Reservatório de água do Açude Sumé.

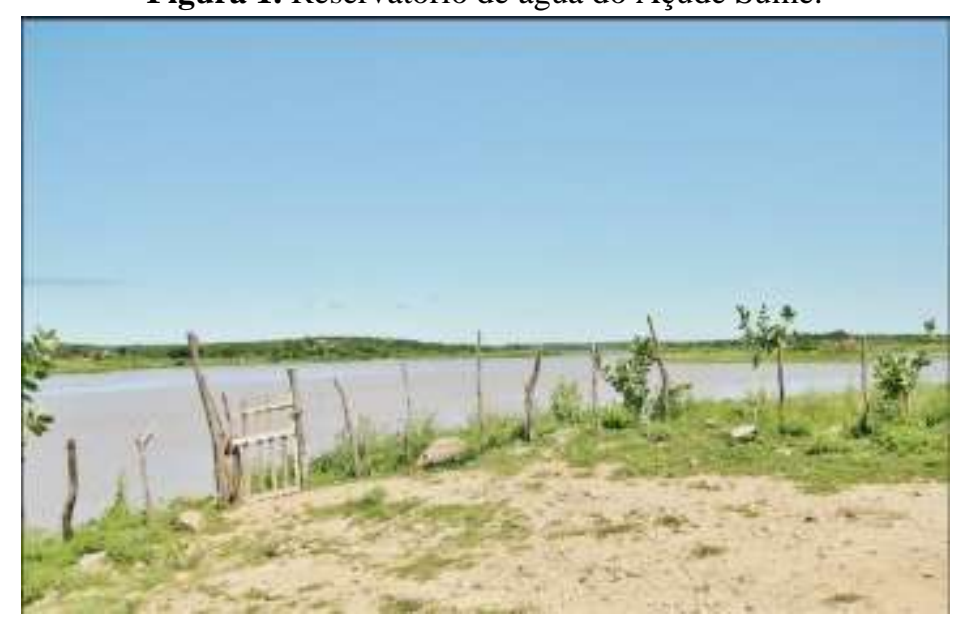

Fonte: Costa (2018).

De acordo com o Plano Diretor da bacia do Rio Paraíba (2001) o açude Sumé compreende uma extensão de 856,25 $\mathrm{km}^{2}$. Possui uma tendência a enchentes nas regiões mais baixas (no entorno do açude) e secas nos períodos críticos (Alexandre, 2012). A forma da bacia é arredondada e composta por 631 açudes. Seu volume máximo chega a atingir $44.864 .100 \mathrm{~m}^{3}$.

\subsection{Aplicação dos instrumentos de gestão dos recursos hídricos.}

\subsubsection{Plano Diretor}

Trata-se de um estudo aprofundado e orienta quanto as alternativas ideais para utilização e manejo das águas de uma bacia hidrográfica. Este planejamento auxilia na tomada de decisão, de modo a produzir os melhores resultados econômicos, sociais e ambientais (Figura 2).

Em relação ao Açude Sumé, o levantamento de informações, órgãos competentes e a sociedade civil atuante são encontrados a seguir:

- Instalação do Comitê da Bacia Hidrográfica do rio Paraíba, já aprovado pelo Conselho Estadual de Recursos Hídricos, como um órgão colegiado, de caráter consultivo e deliberativo que comporá o Sistema Integrado de Planejamento e Gerenciamento de Recursos Hídricos do Estado;

- Regimento interno do comitê da bacia hidrográfica do Rio Paraíba do estado da Paraíba;

- Decreto ${ }^{\circ} 27.560$ de 04 de setembro de 2006, que Cria o comitê do Rio Paraíba;

- Assoc. dos Moradores e Usuários de Águas da Bacia do Açude Sumé - AMUABAS- Vital Rodrigues Filho - Sumé;

- Cooperativa Agrícola Mista dos Irrigantes de Sumé - José Ivanildo Aleixo de Souza - Sumé;

- Plano Diretor de recursos hídricos da bacia hidrográfica do Rio Paraíba 2001. 
Figura 2. Mapa geológico e geomorfológico do Rio Paraíba abrangendo a bacia hidráulica de Sumé.

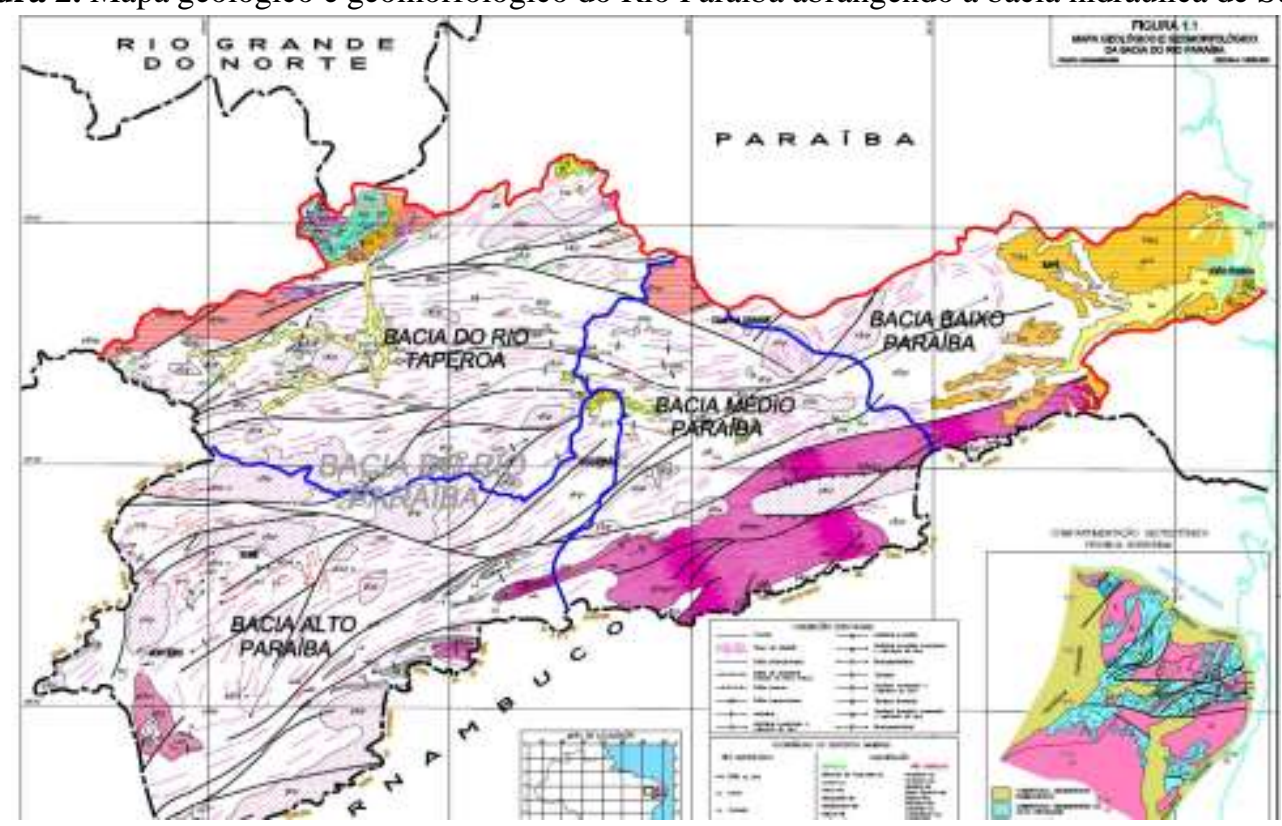

Fonte: Plano diretor do Rio Paraíba (2001).

Observa-se na Figura 2 as bacias hidrográficas que se localizam nas proximidades do Rio Paraíba, que subsequente abrange o leito da bacia hidráulica de Sumé.

A vegetação natural predominante na área de estudo é a Caatinga Hiperxerófila, com um conjunto de porte arbóreo baixo ou arbóreo arbustivo (Figura 3). A vegetação da caatinga possui alta capacidade de adaptação à escassez hídrica; seus recursos bioquímicos e físicos a tornam altamente adaptada aos longos períodos de estiagem da região (Berlamino, 2017).

Figura 3. Mapa de uso e ocupação de solo da bacia hidrográfica do Rio Paraíba.

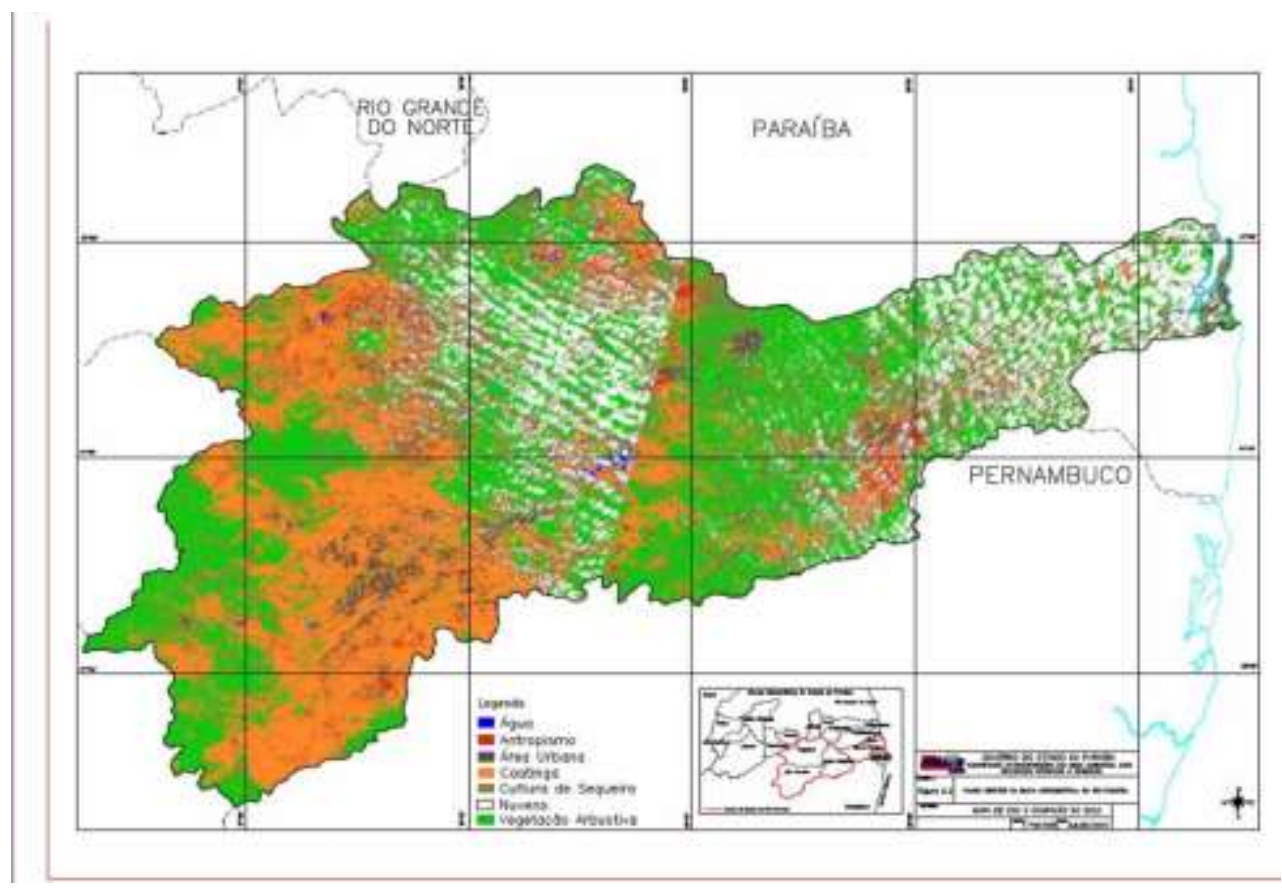

Fonte: Plano diretor da bacia do Rio Paraíba (2001).

Pode ser observado o desenvolvimento de atividades realizadas através da ocupação da bacia hidrográfica do rio paraíba, as formas de manejos e uso desse recurso hídrico. 


\subsubsection{Plano Municipal de Saneamento do município Prata-PB}

O município da Prata está localizado na Mesorregião da Borborema e na Microrregião do Cariri Ocidental. Sua população foi estimada em 2010 pelo IBGE (IBGE, 2010) em 3.854 habitantes, o município ocupa uma área de $192.012 \mathrm{~km}^{2} \mathrm{e}$ limita-se com o estado de Pernambuco e com os municípios de Ouro Velho, Amparo, Sumé e Monteiro (Esselin, 2011). O clima predominante no município da Prata é do tipo Tropical Semiárido, com chuvas de verão. O período chuvoso se inicia em novembro com término em abril. A precipitação média anual é de 431,80mm (Malvestio, 2013).

Quanto ao consumo per capita e consumidores especiais no município foram utilizadas informações do SNIS (2011) onde o município informa que o consumo per capita é de 120,00 L/hab dia, não havendo informação quanto a consumidores especiais (Barbosa, 2017). O abastecimento de água na sede do município atualmente é feito unicamente pelo sistema adutor do Congo, que capta água do Açude Cordeiros e distribui para o município, mas segundo informações da Companhia de Água existe no município um outro sistema de abastecimento, que utiliza água do manancial Prata II, e abastece a cidade, e também mananciais subterrâneos (poços artesianos). Existem dois corpos de acumulação dentro do município: o Açude Prata I e Prata II. Os dois açudes encontram-se desativados, devido ao seu estado crítico, sua qualidade deteriorada, sendo que o Açude Prata II encontra-se praticamente seco.

A concepção do sistema de abastecimento de água na Sede da Prata é composto por 1 ponto de captação em nascentes, com todo o tratamento realizado de forma simplificada. No sistema de distribuição está instalado 1 reservatório que atende a distribuição de água (Silveira, 2020). Toda esta infraestrutura implantada tem a função de abastecer aproximadamente 796 famílias que corresponde a 66,2\% do total de habitantes do município e 100\% da área urbana (Pereira, 2020).

\subsubsection{Plano Municipal de Gestão Integrada de Resíduos Sólidos no município de Sumé-PB}

As exigências legais para o planejamento da gestão de resíduos sólidos vêm tanto da Lei Federal de Saneamento Básico (Lei 11.445/2007) quanto da Lei que institui a Política Nacional de Resíduos Sólidos (Lei12.305/2010) e o Decreto $\mathrm{n}^{\circ}$ 7.404, de 23 de dezembro de 2010 que a regulamenta. O principal objetivo da elaboração de Planos Municipais de Gestão Integrada de Resíduos Sólidos é dar subsídio, via Governo Federal e cooperação com Municípios, para a administração integrada dos resíduos por meio de um conjunto de ações normativas, operacionais, financeiras e de planejamento (Pereira \& Curi, 2013).

A cidade contém cerca de 4.109 domicílios particulares urbanos, destes um total de 298 possuem sistema de esgotamento sanitário, 3.838 são atendidos pelo sistema estadual de abastecimento de água e outros 3.906 com coleta de lixo (Cossenzo, 2013). No setor de saúde o serviço é prestado por 1 hospital e 14 unidades ambulatoriais. A educação conta com recurso de 16 estabelecimentos de ensino fundamental. A agricultura e a pecuária constituem as principais atividades econômicas da comunidade. O total de empresas atuantes com CNPJ é em número de 33 (Azevêdo, 2017).

\subsection{Sistemas de Informações}

O instrumento Sistema de Informações sobre Recursos Hídricos, previsto na Lei n 9.433, de 8 de janeiro de 1997, que institui a Política Nacional de Recursos Hídricos e cria o Sistema Nacional de Gerenciamento de Recursos Hídricos, é um sistema de coleta, tratamento, armazenamento e recuperação de informações sobre recursos hídricos e fatores intervenientes em sua gestão (Mesquita, 2018).

De acordo com a Agência Nacional das Águas (ANA, 2019) os volumes observados entre o período de Jun/2019 e o esperado apresentam pouca variabilidade. Apresenta uma média de 2,32 $\mathrm{hm}^{3}$. Abaixo, segue o gráfico mostrando o quantitativo dos valores observados e esperados. 
Figura 1. Volumes Esperados e Observados do Açude Sumé disponível pela Agência Nacional das Águas (2019).

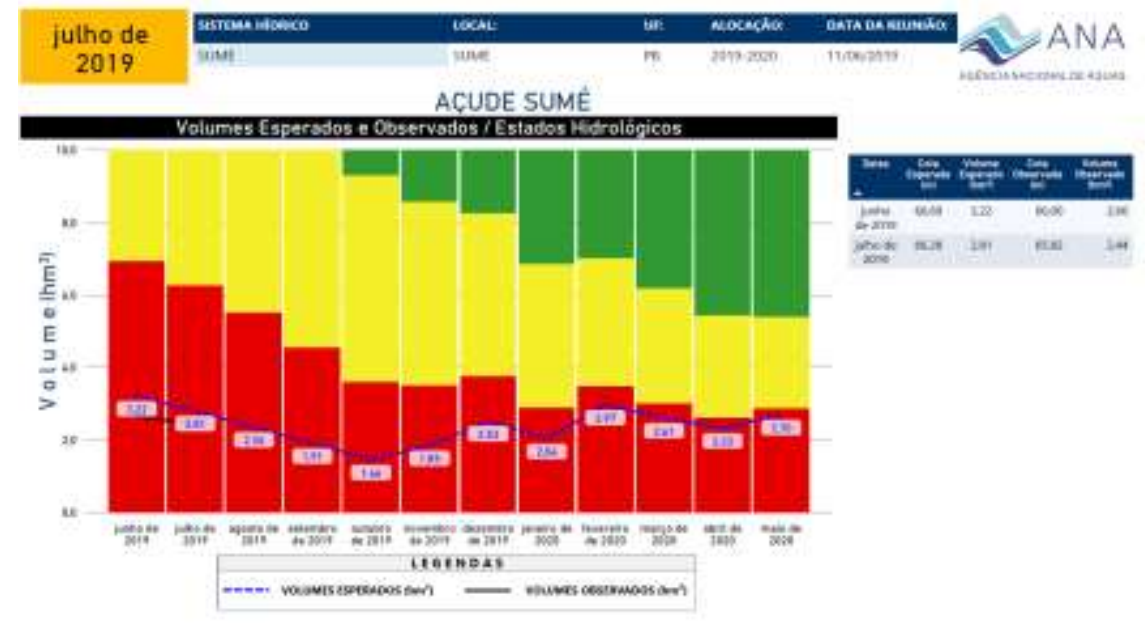

Fonte: Ana (2019).

Em relação ao monitoramento da bacia hidráulica de Sumé as cotas do reservatório são realizadas pelo DNOCS com frequência diária. Os volumes captados para abastecimento público são de responsabilidade da CAGEPA. Além do controle de qualidade de água como o caso do tratamento e distribuição para população.

\subsection{Enquadramento dos corpos d'água}

Segundo Fagundes (2016), o enquadramento dos corpos de água segundo seus usos preponderantes visa assegurar às águas qualidade compatível com os usos mais exigentes a que forem destinadas, subsidiando o processo de concessão de outorga de direitos de uso dos recursos hídricos e, diminuir os custos de combate à poluição das águas, mediante ações preventivas permanentes (Bias, 2013).

A AESA - Agência Executiva de Gestão das Águas do Estado da Paraíba apresenta um trabalho realizado em 1988 sobre qualidade e enquadramento dos corpos d'água realizado em toda a bacia do Rio Paraíba com classe 2 (Fagundes, 2016). Em geral há uma fragmentação ao longo da sua extensão associado aos usos e principalmente as outorgas Diante desta realidade, as informações não explicam a situação dos corpos d'água atual do açude Sumé. Para isso alguns trabalhos recentemente investigaram informações já estudadas anteriormente (Souza, 2014).

\section{Resultados e Discussão}

Os resultados obtidos foram encontrados através de duas pesquisas, onde uma delas consiste no estudo de qualidade de água do açude Sumé, através de parâmetros físicos da água. Em contrapartida foram investigados também através de uma amostra qualitativa da opinião dos consumidores com relação a qualidade da água do abastecimento na cidade de Sumé-PB, além do mais avaliar o controle de qualidade de água e sua distribuição por meio da outorga.

\subsection{Pesquisa 1: estudo qualitativo da água do açude Sumé, através de parâmetros físicos.}

A partir da análise dos resultados, concluiu-se que as amostras de água dos pontos a mostrais estudados, principalmente os das primeiras coletas, não estão em conformidade com os padrões de potabilidade segundo a Portaria 2914/11 do MS e a Resolução 357/05 do CONAMA. Os parâmetros demonstraram discordância com as legislações reguladoras (CONAMA e MS), por estarem submetidos a períodos de secas prolongados e a perderem maior volume de água devido ao efeito da evaporação (Fagundes, 2016). 
Os valores alterados dos parâmetros: turbidez, CE, STD; revelam que há uma grande quantidade de sólidos dissolvidos, acima dos padrões de potabilidade, destacando-se as duas primeiras coletas ( $1^{\mathrm{a}}, 2^{\mathrm{a}}$ coleta). Esses resultados podem ser provocados tanto pelo antropismo, e pelo agravamento do período de seca prolongada, perdendo maior volume de água devido ao efeito da evaporação.

\subsection{Pesquisa 2: amostra qualitativa da opinião dos consumidores com relação à qualidade da água do abastecimento na cidade de Sumé-PB.}

Pode-se concluir que, segundo a percepção dos consumidores, existem alterações na qualidade da água, tais como cheiro, cor ou turbidez da água. Uma das possibilidades, de acordo com referenciais teóricos, é que mesmo com a realização do tratamento de água pela CAGEPA, este não está tendo a eficácia prevista, em virtude do baixo volume atual do reservatório com 7,2 \%, segundo os dados da AESA para o mês de agosto 2016 (Rocha et al., 2016).

\subsection{Outorga}

A outorga é o instrumento da Política de Recursos Hídricos que tem o objetivo de assegurar o controle quantitativo e qualitativo dos usos da água. Garante ao usuário outorgado o direito de acesso à água, uma vez que regulariza o seu uso em uma bacia hidrográfica (ANA, 2011). Na região do alto do Rio Paraíba os mananciais compreendem entre poço e açude. Especificamente, em Sumé, o abastecimento público é feito pela CAGEPA através de açude. Segue a Tabela 1 com todas as informações referente as outorgas da região do alto do Rio Paraíba.

Tabela 1. Histórico de outorgas da região do alto do Rio Paraíba nos períodos de 2006 a 2014.

\begin{tabular}{|c|c|c|c|c|c|c|}
\hline $\begin{array}{l}\text { Nome do } \\
\text { usuário }\end{array}$ & Bacia & $\begin{array}{c}\text { Tipo de } \\
\text { Uso }\end{array}$ & $\begin{array}{l}\text { Fonte } \\
\text { Hídrica }\end{array}$ & Manancial & $\begin{array}{c}\text { Vazão } \\
\text { Horária } \\
\left(\mathrm{m}^{3} / \mathrm{h}\right)\end{array}$ & Data de Expiração \\
\hline AGUBEL & $\begin{array}{c}\text { Alto do } \\
\text { Rio } \\
\text { Paraíba }\end{array}$ & Industrial & & Poço & 6 & 2008 \\
\hline $\begin{array}{l}\text { Alexandre } \\
\text { Campos }\end{array}$ & $\begin{array}{c}\text { Alto do } \\
\text { Rio } \\
\text { Paraíba }\end{array}$ & Irrigação & & Poço & 25 & 2008 \\
\hline $\begin{array}{l}\text { Amaury } \\
\text { Aragão }\end{array}$ & $\begin{array}{c}\text { Alto do } \\
\text { Rio } \\
\text { Paraíba }\end{array}$ & Irrigação & & Poço & 12 & 2012 \\
\hline $\begin{array}{c}\text { Antonio } \\
\text { Alves }\end{array}$ & $\begin{array}{c}\text { Alto do } \\
\text { Rio } \\
\text { Paraíba }\end{array}$ & Irrigação & & Poço & 25 & 2008 \\
\hline $\begin{array}{l}\text { Aroldo } \\
\text { Barros }\end{array}$ & $\begin{array}{c}\text { Alto do } \\
\text { Rio } \\
\text { Paraíba }\end{array}$ & Irrigação & & Poço & 22.22 & 2006 \\
\hline $\begin{array}{l}\text { Associação } \\
\text { P.R.E.Tigre }\end{array}$ & $\begin{array}{c}\text { Alto do } \\
\text { Rio } \\
\text { Paraíba }\end{array}$ & $\begin{array}{l}\text { Abast. } \\
\text { Público }\end{array}$ & & Poço & 1.7 & 2013 \\
\hline $\begin{array}{l}\text { Associação } \\
\text { P.R.E.Tigre }\end{array}$ & $\begin{array}{c}\text { Alto do } \\
\text { Rio } \\
\text { Paraíba }\end{array}$ & $\begin{array}{l}\text { Abast. } \\
\text { Público }\end{array}$ & & Poço & 1.5 & 2013 \\
\hline Braz Quitans & $\begin{array}{c}\text { Alto do } \\
\text { Rio } \\
\text { Paraíba }\end{array}$ & Irrigação & & Poço & 8.33 & 2006 \\
\hline
\end{tabular}


Research, Society and Development, v. 10, n. 2, e11910212033, 2021

(CC BY 4.0) | ISSN 2525-3409 | DOI: http://dx.doi.org/10.33448/rsd-v10i2.12033

\begin{tabular}{|c|c|c|c|c|c|c|}
\hline CAGEPA & $\begin{array}{c}\text { Alto do } \\
\text { Rio } \\
\text { Paraíba }\end{array}$ & $\begin{array}{l}\text { Abast. } \\
\text { Público }\end{array}$ & & Poço & 15 & 2010 \\
\hline CAGEPA & $\begin{array}{c}\text { Alto do } \\
\text { Rio } \\
\text { Paraíba }\end{array}$ & $\begin{array}{l}\text { Abast. } \\
\text { Público }\end{array}$ & Sumé & Açude & 117 & 2010 \\
\hline CAGEPA & $\begin{array}{c}\text { Alto do } \\
\text { Rio } \\
\text { Paraíba }\end{array}$ & $\begin{array}{l}\text { Abast. } \\
\text { Público }\end{array}$ & & Poço & 15 & 2010 \\
\hline CAGEPA & $\begin{array}{c}\text { Alto do } \\
\text { Rio } \\
\text { Paraíba }\end{array}$ & $\begin{array}{l}\text { Abast. } \\
\text { Público }\end{array}$ & & Poço & 15 & 2010 \\
\hline CAGEPA & $\begin{array}{c}\text { Alto do } \\
\text { Rio } \\
\text { Paraíba }\end{array}$ & $\begin{array}{l}\text { Abast. } \\
\text { Público }\end{array}$ & & Poço & 15 & 2010 \\
\hline $\begin{array}{l}\text { Cosmo } \\
\text { Vieira }\end{array}$ & $\begin{array}{c}\text { Alto do } \\
\text { Rio } \\
\text { Paraíba }\end{array}$ & Irrigação & & Poço & 24.07 & 2006 \\
\hline $\begin{array}{c}\text { Francisco } \\
\text { Tomaz }\end{array}$ & $\begin{array}{c}\text { Alto do } \\
\text { Rio } \\
\text { Paraíba }\end{array}$ & Irrigação & & Poço & 14.81 & 2008 \\
\hline $\begin{array}{c}\text { Frutuoso } \\
\text { Severo }\end{array}$ & $\begin{array}{c}\text { Alto do } \\
\text { Rio } \\
\text { Paraíba }\end{array}$ & Irrigação & & Poço & 4 & 2008 \\
\hline Fábio Freitas & $\begin{array}{c}\text { Alto do } \\
\text { Rio } \\
\text { Paraíba }\end{array}$ & Irrigação & & Poço & 12.03 & 2010 \\
\hline $\begin{array}{c}\text { Joel } \\
\text { Gaudêncio }\end{array}$ & $\begin{array}{c}\text { Alto do } \\
\text { Rio } \\
\text { Paraíba }\end{array}$ & Irrigação & & Poço & 13.89 & 2006 \\
\hline $\begin{array}{c}\text { José } \\
\text { Bonifácio }\end{array}$ & $\begin{array}{c}\text { Alto do } \\
\text { Rio } \\
\text { Paraíba }\end{array}$ & Irrigação & & Poço & 16.66 & 2006 \\
\hline $\begin{array}{c}\text { José } \\
\text { Fernandes }\end{array}$ & $\begin{array}{c}\text { Alto do } \\
\text { Rio } \\
\text { Paraíba }\end{array}$ & Irrigação & & Poço & 5 & 2008 \\
\hline José Joelson & $\begin{array}{c}\text { Alto do } \\
\text { Rio } \\
\text { Paraíba }\end{array}$ & Irrigação & & Poço & 18.5 & 2012 \\
\hline José Joelson & $\begin{array}{c}\text { Alto do } \\
\text { Rio } \\
\text { Paraíba }\end{array}$ & Irrigação & & Poço & 18.5 & 2008 \\
\hline $\begin{array}{c}\text { José } \\
\text { Lourivaldo }\end{array}$ & $\begin{array}{c}\text { Alto do } \\
\text { Rio } \\
\text { Paraíba }\end{array}$ & Irrigação & & Poço & 12.03 & 2014 \\
\hline João Batista & $\begin{array}{c}\text { Alto do } \\
\text { Rio } \\
\text { Paraíba }\end{array}$ & Irrigação & $\begin{array}{c}\text { Terra } \\
\text { Vermelha }\end{array}$ & Açude & 20 & 2008 \\
\hline $\begin{array}{l}\text { Lindberg } \\
\text { Farias }\end{array}$ & $\begin{array}{c}\text { Alto do } \\
\text { Rio } \\
\text { Paraíba }\end{array}$ & Irrigação & & Poço & 35 & 2008 \\
\hline $\begin{array}{c}\text { Lourival } \\
\text { Alves }\end{array}$ & $\begin{array}{l}\text { Alto do } \\
\text { Rio }\end{array}$ & Irrigação & & Poço & 19.44 & 2006 \\
\hline
\end{tabular}


Research, Society and Development, v. 10, n. 2, e11910212033, 2021

(CC BY 4.0) | ISSN 2525-3409 | DOI: http://dx.doi.org/10.33448/rsd-v10i2.12033

\begin{tabular}{|c|c|c|c|c|c|c|}
\hline & Paraíba & & & & & \\
\hline Luis Quitans & $\begin{array}{c}\text { Alto do } \\
\text { Rio } \\
\text { Paraíba }\end{array}$ & Irrigação & & Poço & 19.44 & 2006 \\
\hline $\begin{array}{l}\text { Manoel } \\
\text { Batista }\end{array}$ & $\begin{array}{c}\text { Alto do } \\
\text { Rio } \\
\text { Paraíba }\end{array}$ & Irrigação & & Poço & 13.89 & 2006 \\
\hline $\begin{array}{c}\text { Maria } \\
\text { Francisca }\end{array}$ & $\begin{array}{c}\text { Alto do } \\
\text { Rio } \\
\text { Paraíba }\end{array}$ & Irrigação & & Poço & 19.44 & 2009 \\
\hline $\begin{array}{c}\text { Maria } \\
\text { Francisca }\end{array}$ & $\begin{array}{c}\text { Alto do } \\
\text { Rio } \\
\text { Paraíba }\end{array}$ & Irrigação & & Poço & 19.44 & 2006 \\
\hline $\begin{array}{l}\text { Prefeitura } \\
\text { Sumé }\end{array}$ & $\begin{array}{c}\text { Alto do } \\
\text { Rio } \\
\text { Paraíba }\end{array}$ & $\begin{array}{l}\text { Abast. } \\
\text { Público }\end{array}$ & $\begin{array}{c}\text { Açude N. } \\
\text { Sra. da } \\
\text { Penha }\end{array}$ & Poço & 4.97 & 2011 \\
\hline Santa Maria & $\begin{array}{c}\text { Alto do } \\
\text { Rio } \\
\text { Paraíba }\end{array}$ & Irrigação & & Açude & 144 & 2008 \\
\hline $\begin{array}{l}\text { Sebastiana } \\
\text { Morais }\end{array}$ & $\begin{array}{c}\text { Alto do } \\
\text { Rio } \\
\text { Paraíba }\end{array}$ & Irrigação & & Poço & 3 & 2008 \\
\hline $\begin{array}{l}\text { Severino dos } \\
\text { Ramos }\end{array}$ & $\begin{array}{c}\text { Alto do } \\
\text { Rio } \\
\text { Paraíba }\end{array}$ & Irrigação & & Poço & 24.07 & 2006 \\
\hline $\begin{array}{c}\text { Vitorino } \\
\text { Cavalcante }\end{array}$ & $\begin{array}{c}\text { Alto do } \\
\text { Rio } \\
\text { Paraíba }\end{array}$ & Irrigação & & Poço & 18.9 & 2009 \\
\hline
\end{tabular}

Fonte: Autores (2021).

Observando-se a Tabela 1 percebe-se a distribuição total das outorgas da região do alto do Rio Paraíba nos períodos de 2019 a 2020 Destacando o tipo de uso de manancial e a forma de extração, levando em consideração que a maior parte desse recurso é extraído por meio de poços artesianos com números de vazões variadas, por outro lado destaca-se o açude de Sumé que entre muitos o seu manancial não é proveniente de poços.

Destaca-se algumas ações utilizadas pelo município de Sumé para fazer o uso eficiente da água estão concentradas na zona rural através das construções de cisternas e no perímetro irrigado da bacia hidráulica de Sumé fazendo o cultivo de culturas resistentes a estiagem e utilizando técnica de gotejamento (Azevêdo, 2017).

\subsection{Cobrança}

A Cobrança pelo Uso de Recursos Hídricos é um dos instrumentos de gestão da Política Nacional de Recursos Hídricos, instituída pela Lei no 9.433/97, e têm como objetivo dar ao usuário uma indicação do real valor da água, incentivar o uso racional deste recurso e obter aporte financeiro para recuperação das bacias hidrográficas. A cobrança não é um imposto, e sim uma remuneração pelo uso de um bem público, cujo preço é fixado a partir da participação dos usuários da água, da sociedade civil e do poder público no âmbito dos Comitês de Bacias Hidrográficas (Marques, 2018).

Em relação a região do alto do Rio Paraíba já existem discussões a respeito da cobrança da água. Abaixo segue o detalhamento das informações sobre a formação dos comitês da bacia do Rio Paraíba, especificamente na região de Sumé e o que vem sendo discutido. 
Tabela 2. Formação dos comitês de bacia do Rio Paraíba.

\begin{tabular}{|c|c|c|}
\hline ATAS & LOCAL & ASSUNTO \\
\hline
\end{tabular}

Ata (1 ${ }^{\text {a }}$ reunião extraordinária) 2010

UFCG/Campina Grande
Revisão do regimento interno do CBH-PB; Leitura do ofício n⿳032/2009-ajuda quanto ao destino das águas (300 famílias) que moram no em torno do açude estão sem água.

\begin{tabular}{ll}
\hline Ata $\left(1^{\text {a }}\right.$ reunião extraordinária) 2014 & $\begin{array}{l}\text { Colégio Estadual da Prata em } \\
\text { Campina Grande-PB. }\end{array}$
\end{tabular}

Ata ( $1^{a}$ reunião extraordinária)2015 Colégio Estadual da Prata em Campina Grande-PB.

Apresentação da CAGEPA sobre situação atual e futura do esgotamento sanitário dos municípios ao longo da bacia do Rio Paraíba (CG, Sumé, Camalaú e Monteiro); Apresentação da ANA em relação a situação do Açude de Boqueirão; Apresentação da AESA sobre a situação hídrica do Estado;

Ata (2 $2^{a}$ reunião extraordinária)2015 CENTRAC em Campina Grande-PB.

Apresentação do projeto de revitalização do Rio Paraíba; Aprovação da Ata ( $1^{\text {a }}$ reunião extraordinária) 2015.
CENTRAC em Campina Grande-PB.
Aprovação da Ata da $\left(2^{\mathrm{a}}\right.$ reunião extraordinária) do CBH-PB; Apresentação das licenças concedidas e das ações realizadas para fiscalização do cumprimento das suas condicionantes aos projetos de Carcinicultura e Psicultura das cidades do Vale do Paraíba (SUDEMA);

Ata da ( $1^{\text {a }}$ Reunião extraordinária) $2016 \quad$ CENTRAC em Campina Grande-PB

CENTRAC em Campina Grande-PB
Auditório do SENGE em Campina Grande-PB
Aprovação da ata da $2^{\mathrm{a}}$ Reunião Ordinária do CBH-PB; Apresentação sobre o sistema Boqueirão (CAGEPA); Apresentação da metodologia e calendário sobre a formação da comissão gestora do Açude de Boqueirão.

Planejamento para as reuniões em 2017; Plano de Aplicação dos Recursos de Cobrança; Proposta de aplicação dos recursos da cobrança pelo uso da água bruta;

Ata da (1ª Reunião extraordinária) 2018 CENTRAC em Campina Grande-PB

Hotel Village em Campina GrandePB.
Apresentação do Projeto do Sistema da Adutora TransParaíba; Deliberação da Comissão Eleitoral para o Processo Eleitoral do CBH-PB.

Sra. Myrla de Souza da AESA proferiu a palestra "Recursos Hídricos: Noções Básicas"; Sra. Ana Emília Duarte proferiu a palestra "Noções sobre gestão dos Recursos Hídricos"; Sra. Maria do Socorro Mendes ministrou a palestra "Noções sobre legislação dos Recursos Hídricos do estado de Pernambuco";

Eleição do novo secretário do comitê; Continuidade da discussão sobre a proposta da cobrança da água bruta; Meios de transportes lavados no Rio Paraíba (ações poluidoras); 
Ata da $2^{\mathrm{a}}$ Reunião Ordinária do CBH-PB UFCG (Campina Grande-PB) 2008

Normatizar presença dos membros; Discussão do Plano de trabalho do CBH-PB 2008; Correspondência aos faltosos;

Discussão sobre a convocação dos membros e o novo processo eleitoral; Falta de discussões sobre o Projeto PISF; Inauguração do Programa Água Doce em Amparo-PB.

Ata da $1^{\text {a }}$ Reunião Ordinária do CBH-PB UFCG (Campina Grande-PB) 2010

Ata da $1^{\text {a }}$ Reunião Ordinária do CBH-PB UFCG (Campina Grande-PB) 2009

Discussão sobre as dificuldades de reunir quórum; Sugestões para algumas alterações do regimento interno; Sugestão para discussão de outros pontos como o Plano de Bacia Hidrográfica do Rio Paraíba, PISF

Ata da $1^{\text {a }}$ Reunião Ordinária do CBH-PB FIEP-Campina Grande-PB 2011

Importância da parceria dos comitês na gestão dos recursos hídricos; Márcia Almeida proferiu a palestra Legislação dos Recursos Hídricos; Maria de Lourdes proferiu a palestra Importância dos comitês na gestão dos Recursos Hídricos.

Ata da $2^{\text {a }}$ Reunião Ordinária do CBH-PB SENGE-Campina Grande-PB Criação do Fórum de Defesa do Rio 2011 Paraíba; Apresentação do Projeto estruturante e sustentabilidade e gestão em Recursos Hídricos; Discussões sobre a data do Fórum Estadual de Comitês.

Ata da $1^{\text {a }}$ Reunião Ordinária do CBH-PB SENGE-Campina Grande-PB 2012

Leitura e aprovação da Ata anterior; Discussão sobre a retirada mecanizada de areia do Rio Paraíba bem como o uso e ocupação do solo; Apresentação de agenda de atividades do comitê 2012; Composição da comissão do comitê.

Ata da $2^{\mathrm{a}}$ Reunião Ordinária do CBH-PB CENTRAC em Campina Grande-PB 2012

Leitura e aprovação da Ata anterior; Discussão sobre uma instalação de usina de energia no açude de Boqueirão; Apresentação da situação da execução do Projeto de Integração das bacias do NE Setentrional a Bacia Hidrográfica do Rio São Francisco;

Ata da $1^{\text {a }}$ Reunião Ordinária do CBH-PB 2014

Ata da $2^{\mathrm{a}}$ Reunião Ordinária do $\mathrm{CBH}-\mathrm{PB}$ 2014
CIAC (UEPB) em Campina GrandePB.
Ata da assembleia de posse eleição da diretoria colegiada;
Colégio Estadual da Prata em Campina Grande-PB.
Leitura e aprovação da ata da sessão anterior; Apresentação atual dos açudes do estado da Paraíba; Discussões sobre a falta d'água na cidade de Boa Ventura e Diamante no Vale do Piancó; Apresentação do Plano Municipal de Saneamento Básico.

Apresentação do novo Diretor de Gestão e Apoio Estratégico da AESA; Informes de diretoria; Aprovação da ata da $2^{\mathrm{a}}$ reunião ordinária e $1^{\text {a }}$ reunião extraordinária; Projeto de Revitalização do Rio Paraíba.
Ata da $1^{\mathrm{a}}$ Reunião Ordinária do $\mathrm{CBH}-\mathrm{PB}$ 2015
Colégio Estadual da Prata em Campina Grande-PB.
Aprovação da Ata da $3^{\mathrm{a}}$ Reunião Extraordinária do CBH-PB; Apresentação do Projeto "Cobrança pelo uso da água bruta: aspectos operacionais de implementação do estado da Paraíba”. 


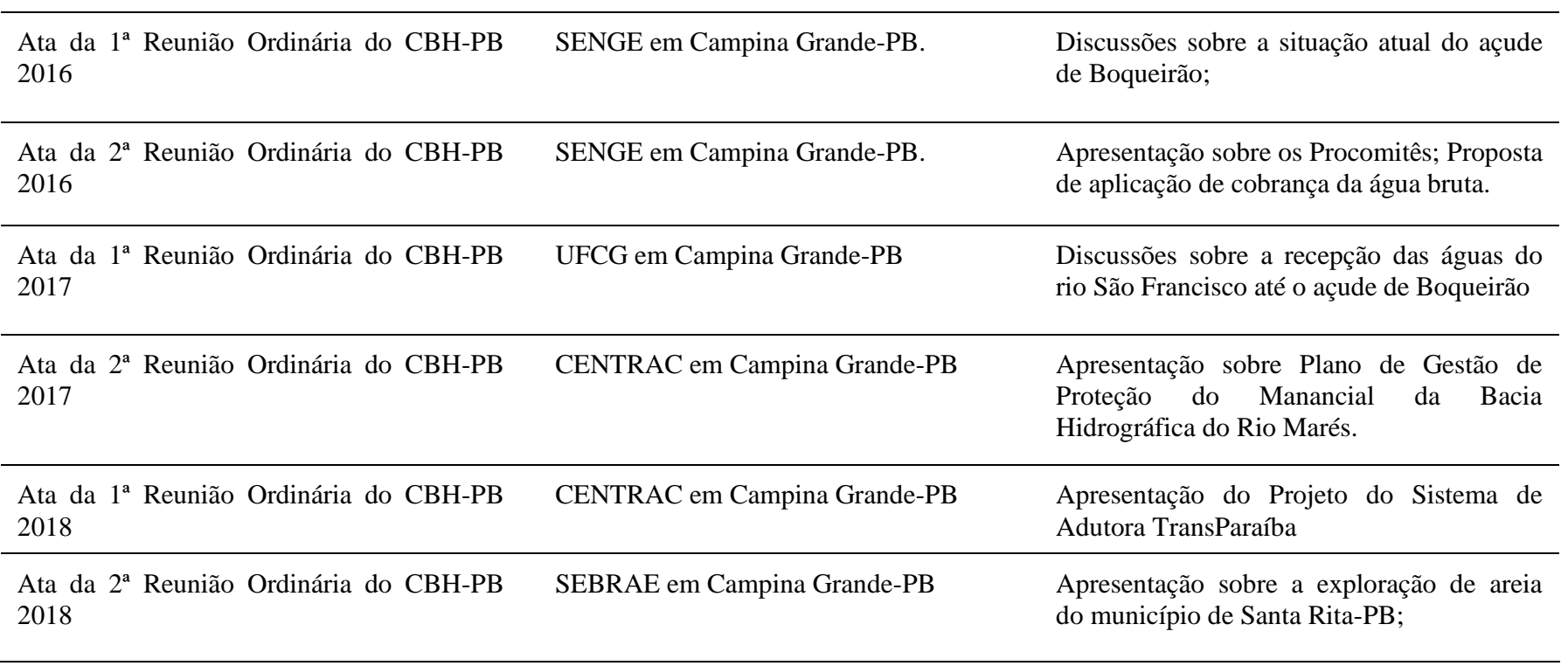

Fonte: Autores (2021).

Na Tabela 2 citada mostra-se a formação do comitê de bacias do rio paraíba, o Conselho Estadual de Recursos Hídricos, o Controle Técnico de Obras e Serviços de Oferta Hídrica e a Outorga de Direito de Uso da Água. Em seguida, por solicitação da SEPLAN/Grupo Gestor de Recursos Hídricos, os mesmos técnicos elaboraram o documento "Avaliação da Infraestrutura Hídrica e do Suporte para o Sistema de Gerenciamento de Recursos Hídricos do Estado da Paraíba", através do qual foram levantadas as principais obras de captação (açudes e poços), as potencialidades disponibilidades hídricas e as demandas de água por bacia hidrográfica.

\section{Conclusão}

A partir deste estudo podemos afirmar que o solo da cidade de Sumé é considerado inapto para uso agrícola devido ao fato de que seu solo e subsolo possui uma baixa capacidade de permeabilidade atrelado ao seu clima seco e como baixo índice pluviométrico. Em se tratando da vegetação a cidade de Sumé apresenta predominância da caatinga, que tem como principal característica a capacidade de adaptação a escassez hídrica além disso, fora observado que a população sofre com a falta de saneamento básico o que contribui ainda mais para poluição do solo e da água que por ventura tenha contato a esses insumos seja através do despejo direto no leito das bacias hidrográficas e por escoamento superficial e/ou subsuperficial.

Desta forma, faz-se necessário o uso racional e melhoramento da qualidade da água, visto que o reservatório nos dias atuais não se encontra com volume de água capaz de abastecer toda a cidade e redondezas de forma continua sem intercalar o abastecimento, além de ser observado pela população a presença de impurezas e irregularidade na sua qualidade.

Diante disto, verifica-se a importância dos instrumentos de gestão dos recursos hídricos para o conhecimento das características socioeconômicas e naturais da bacia do rio paraíba, onde destaca-se o açude de Sumé, no que tange o conhecimento da base de dados públicos que oportunizem investimentos e qualidade para o melhoramento do uso da água na região, como também a prevenção e manutenção desta bacia. Pois é a partir dessa gama de informações que os governadores podem propor medidas para o melhoramento na distribuição e qualidade da água levando sempre em consideração que esse é um recurso natural finito.

Como sugestão para trabalhos futuros pode-se realizar análise laboratorial e testes de qualidade de água que é distribuído a população de Sumé. Além disso, pode ser realizado pesquisa sobre as questões meteorológicas da região em questão e correlacionar com a demanda do consumo de água pela população local. 


\section{Referências}

AESA - Agência Executiva de Gestão das Águas do Estado da Paraíba. Volume dos Açudes. <http://www.aesa.pb.gov.br/aesawebsite/monitoramento/ultimosvolumes/>.

Alexandre, D. M. B. (2012). Gestão de pequenos sistemas hídricos no semiárido nordestino. 151 f. Tese (Doutorado) - Universidade Federal do Ceará, Centro de Ciências Agrárias, Departamento de Engenharia Agrícola, Programa de Pós-Graduação em Engenharia Agrícola, Fortaleza-CE.

Amorim, J. D. de. Diagnóstico do perímetro irrigado da cidade de Sumé - PB. 2017. 43f. (Trabalho de Conclusão de Curso - Monografia), Curso de Engenharia de Biotecnologia e Bioprocessos, Centro de Desenvolvimento Sustentável do Semiárido, Universidade Federal de Campina Grande, Sumé Paraíba - Brasil.

Azevêdo, A. C. D. (2017). AUTONOMIA X DEPENDÊNCIA: políticas de água no Semiárido e desenvolvimento regional (Doctoral dissertation, 00500 Universidade de Coimbra).

Barbosa, V. V. (2017). Cenários de mudanças climáticas e ambiente: influência da variabilidade do clima na produção de leite do Agreste de Pernambuco, Brasil (Master's thesis, Universidade Federal de Pernambuco).

Belarmino, M. R. A. Adaptações vegetacionais da caatinga à seca: concepções dos alunos de uma escola pública do município de Damião-PB. 2017.89 fl. (Trabalho de Conclusão de Curso - Monografia), Curso de Licenciatura em Ciências Biológicas, Centro de Educação e Saúde, Universidade Federal de Campina Grande, Cuité - Paraíba - Brasil.

Bias, E. D. S., Barbosa, F. L. R., \& Brites, R. S. (2013). Emprego de imageamento passivo na análise da variabilidade espacial da turbidez no espelho d'água do Lago Paranoá, Distrito Federal. Engenharia Sanitaria e Ambiental, 18(1), 55-64.

Cardoso, C. A., Dias, H. C. T., Soares, C. P. B., \& Martins, S. V. (2006). Caracterização morfométrica da bacia hidrográfica do rio Debossan, Nova Friburgo, RJ. Revista árvore, 30(2), 241-248.

Calado, T. de O. (2020). Análise da relação do uso do solo com a qualidade da água do açude Epitácio Pessoa no Eixo Leste do Projeto de Integração do Rio São Francisco. 2020. Dissertação (Mestrado em Desenvolvimento e Meio Ambiente) - Universidade Federal de Pernambuco, Recife.

Censo, I. B. G. E. (2010). <http://www. Censo 2010. ibge. gov. br/>.

Cossenzo, C. L. (2013). Tarifa social dos serviços de abastecimento de água e esgotamento sanitário no Distrito Federal. 2013. xiii,105 f. Dissertação (Saúde Pública) - Escola Nacional de Saúde Pública Sergio Arouca, Rio de Janeiro.

Departamento Nacional de Obras contra a seca (DNOCS).

Esselin, P. M. (2011). A pecuária bovina no processo de ocupação e desenvolvimento econômico do pantanal sul-mato-grossense (1830-1910). Dourados, MS: Ed. Universidade Federal da Grande Dourados, 2011. 358 p.

Fagundes, A. K. B., Mendes, T. A., \& Pereira, T. S. R. (2016). Classificação preliminar de corpos d'água com base na resolução CONAMA n 357/2005: Caso do rio Meia Ponte-GO. Ciência e Natura, 38(3), 1382-1393.

Foleto, E. M. (2018). O contexto dos instrumentos de gerenciamento dos recursos hídricos no brasil. Geoambiente On-Line, (30).

Lima, J. M. D. (2020). Análise da influência hidráulica no sistema de adução da CGH taipinha (Bachelor's thesis).

Malvestio, L. M. (2013). Variabilidade da precipitação pluviométrica da região sudeste do Brasil no período chuvoso e suas consequências ambientais. 137 p. Dissertação (mestrado) - Universidade Estadual de Campinas, Instituto de Geociências, Campinas, SP.

Marques, F. D. P. C. D., \& Resende, S. (2018). Estudo jurídico-comparativo: a cobrança pelo uso da água nos perímetros públicos irrigados do Sertão da Paraíba-PISG e DPIVAS. 39 f. Artigo (Mestrado Profissional em Sistemas Agroindustriais) - Programa de Pós-Graduação em Sistemas Agroindustriais, Centro de Ciências e Tecnologia Agroalimentar, Universidade Federal de Campina Grande, Pombal, Paraíba, Brasil.

Miranda, S., Dantas, S. M., \& Brasileiro, I. M. N. Estudo qualitativo da água do açude Sumé, através de parâmetros FÍSICOS. 2017.

Mesquita, L. F. G. (2018). Os comitês de bacias hidrográficas e o gerenciamento integrado na Política Nacional de Recursos Hídricos. Desenvolvimento e Meio Ambiente, 45.

Plano diretor de recursos hídricos da bacia hidrográfica do Rio Paraíba, vol I, 2001.

Porto, M. F., \& Porto, R. L. L. (2008). Gestão de bacias hidrográficas. Estudos avançados, 22(63), 43-60.

Pereira, S. S., \& Curi, R. C. (2013). Modelos de gestão integrada dos resíduos sólidos urbanos: a importância dos catadores de materiais recicláveis no processo de gestão ambiental. Gestão sustentável dos recursos naturais: uma abordagem participativa [online]. Campina Grande: EDUEPB, $149-172$.

Pereira Junior, J. (2020). Condomínios logísticos, integração das atividades econômicas e a aceleração da reprodução do capital: uma análise do condomínio logístico Bresco Viracopos em Campinas (SP). Pós-Graduação em Geografia Dissertações - Geografia - IGCE.

Rocha, L. C. A., do Nascimento Ribeiro, G., da Costa Medeiros, P., de Alcântara, H. M., de Barros, M. R. G., \& de Medeiros, A. C. (2016). Degradação ambiental no entorno da bacia hidráulica do açude de Sumé-PB. ACTA SUMEENSIS NO SEMIÁRIDO, 1(1).

Silva, S. A. F. D. (2016). Análise multicritério espacial no gerenciamento dos recursos hídricos no perímetro irrigado de Sumé-PB. 149 f. Dissertação (Mestrado em Engenharia Civil e Ambiental) - Centro de Tecnologia e Recursos Naturais, Universidade Federal de Campina Grande, Paraíba, Brasil. 
Research, Society and Development, v. 10, n. 2, e11910212033, 2021

(CC BY 4.0) | ISSN 2525-3409 | DOI: http://dx.doi.org/10.33448/rsd-v10i2.12033

Silveira, R. N. C. M. (2020). Drenagem e Controle de Salinidade na Irrigação.

Souza, J. R. D., Moraes, M. E. B. D., Sonoda, S. L., \& Santos, H. C. R. G. (2014). A importância da qualidade da água e os seus múltiplos usos: caso Rio Almada, sul da Bahia, Brasil. REDE-Revista Eletrônica do Prodema, 8(1).

Souza, B. I., Suertegaray, D. M. A., \& de Lima, E. R. V. (2010). Políticas públicas, uso do solo e desertificação nos Cariris Velhos (PB/Brasil). Scripta Nova. Revista Electrónica de Geografía y Ciencias Sociales, 14.

Sustentável, Produção agroecológica integrada e., brasileiro, no semiárido. Capítulo IX. Difusão de Tecnologias Apropriadas para o Desenvolvimento Sustentável do Semiárido Brasileiro, p. 132.

Teodoro, V. L. I., Teixeira, D., Costa, D. J. L., \& Fuller, B. B. (2007). O Conceito de Bacia Hidrográfica e a Importância da Caracterização Morfométrica para o Entendimento da Dinâmica Ambiental Local. Revista Brasileira Multidisciplinar, 11(1), 137-156. 